\title{
Contos De MoHA
}

AUTOR: SOUAG, MOHA.

TÍTUlo ORIGINAL: CONTES À MOHA (inédits)

ANO: 2012

Traduzido por Fedra Rodríguez Hinojosa 
Fedra Rodríguez Hinojosa 1

(Doutora em Estudos da Tradução - UFSC-Florianópolis/SC/Brasil))

kikarh07@gmail.com

$\mathrm{N}$ ascido em 1949, em Boudenib, cidade ao leste do Marrocos, o premiado autor Mohamed Souag dedica-se às artes desde o 1970, quando terminou seus estudos em Letras Modernas. Fundou organizações para as artes da fotografia e do cinema, como o Cine Club Ksar-es-Souk, assim como jornais acadêmicos. Paralelamente, escreveu diversas coletâneas de narrativas e poesias, a primeira delas L'année de la chienne, em 1979. No mesmo ano, começou a colaborar com seus textos na revista francesa Europe. Durante os anos de 1980, além de publicar compilações de poesia e o romance Les années $U$, realizou um documentário, o qual foi laureado no Festival de Cinema de Rabat e no Festival de Cinema Mediterrâneo de Tétouan. Em 1989, L’année de la chienne recebeu o prêmio Radio France Internationale de melhor conto em língua francesa; e em 1998, Souah ganhou o prêmio Grand Atlas pela seleta Les joueurs.

Seus textos carregam simbolismos e regionalismos marroquinos que nos remetem às antigas lendas e contos orais árabes, além de mesclarem elementos do fantástico e conceitos filosóficos. Além disso, cada uma das obras parece abrigar muitas outras, de modo que, mesmo aquelas mais sucintas, desdobram-se em múltiplos eventos e considerações, transformando-se numa fonte inesgotável de reflexões sobre a cultura árabe-berbere, a ética, as relações humanas, entre outros temas.

\begin{tabular}{|l|l|}
\hline La Faim & \multicolumn{1}{|c|}{ A Fome } \\
Un jour un enfant avait faim. Il se mit à & Certo dia, uma criança tinha fome e pôs-se a \\
pleurer. De sa première larme naquit un & chorar. De sua primeira lágrima nasceu um \\
grain de blé, de sa seconde larme une goutte & grão de trigo, da segunda lágrima, uma gota \\
d'eau et de sa troisième larme un rayon de & de água e da terceira, um raio de sol que \\
soleil qui le mûrit. Un grand épi de blé & amadureceu o grão. Uma grande espiga de \\
poussa. Le vent souffla très fort et toutes les & trigo cresceu. O vento soprou bem forte e \\
graines de l'épi se répandirent partout dans & todas as sementes da espiga se espalharam \\
le ciel. La pluie les arrosa et le soleil les & pelo céu. A chuva os regou e o sol os fez \\
mûrit. La mère du petit enfant les prit, les & amadurecer. A mãe da criança colheu-os e \\
broya et en fit une grosse boule qu'elle fit & moeu-os, para com eles fazer uma massa \\
cuire au soleil .C'est ainsi que la terre devint & grande cozida ao sol. E foi assim que a terra \\
une boule de pain. Tous ceux qui avaient & se transformou numa massa de pão. Todos os \\
\hline
\end{tabular}




\begin{tabular}{|c|c|}
\hline $\begin{array}{l}\text { im en coupaient un morceau et le } \\
\text { angeaient. C'est ainsi que la nuit, quand on } \\
\text { ve les yeux vers le ciel, on voit des milliers } \\
\text { étoiles qui, brillent, ce sont les larme des } \\
\text { tits enfants qui ont faim et qui ne trouvent }\end{array}$ & $\begin{array}{l}\text { que tinham fome cortavam um pedaço dela e } \\
\text { comiam. E é assim que à noite, quando } \\
\text { levantamos os olhos para o céu, vemos } \\
\text { milhares de estrelas que brilham: lágrimas de } \\
\text { crianças que têm fome e não encontram nada } \\
\text { para comer. }\end{array}$ \\
\hline $\begin{array}{l}\text { La Vie et La Mort } \\
\text { a vie et la mort sont deux sœurs jumelles. } \\
\text { lles grandirent ensemble dans le même } \\
\text { erceau et sous le même toit. Bébés, autant } \\
\text { a vie était calme et souriante, autant la mort } \\
\text { tait méchante et pleurnicharde. Elle } \\
\text { nlevait tout à sa sœur. Elle était gourmande. } \\
\text { Céjà petite elle volait le peu de Temps } \\
\text { u'elle attrapait avec ses menottes. Elle } \\
\text { rignotait une seconde par là, une minute } \\
\text { ar ci. Ses parents enfermèrent le Temps } \\
\text { lans une horloge. Quand elle grandit, elle se } \\
\text { nit à avaler les mois et les années. On les } \\
\text { rit et on les fixa dans un calendrier. Mais } \\
\text { ien ne la fit reculer. La vie supportait tous } \\
\text { es caprices de sa sœur. La mort grossissait } \\
\text { ans fin tandis que la vie maigrissait et se } \\
\text { anait à vue d'œil. Elle s'enfuit et alla vivre } \\
\text { illeurs. Elle apportait avec elle, à chaque } \\
\text { ndroit, où elle passait, la joie et le calme; à } \\
\text { on contact les arbres fleurissaient, la terre } \\
\text { erdissait et l'eau coulait en des multitudes } \\
\text { le ruisseaux. Mais la mort la suivait partout } \\
\text { ù elle allait et avalait tout ce que la vie } \\
\text { aisait naître de ses mains. Finalement la } \\
\text { nort avala tout et la terre devint une boule } \\
\text { hauve et désolée. Quand la mort ne trouva } \\
\text { lus une forte indigestion, elle vomit tout ce }\end{array}$ & $\begin{array}{l}\text { A vida e a morte são irmãs gêmeas. } \\
\text { Cresceram juntas no mesmo berço e sob o } \\
\text { mesmo teto. Quando bebês, a vida era calma e } \\
\text { sorridente, enquanto a morte era malvada e } \\
\text { chorona, tirava tudo de sua irmã; era voraz. } \\
\text { Ainda pequena, roubava-lhe o pouco de } \\
\text { Tempo que conseguia agarrar com suas } \\
\text { mãozinhas. Mordiscava um segundo aqui, um } \\
\text { minuto acolá. Seus pais encerraram o Tempo } \\
\text { em um relógio. Quando cresceu, passou a } \\
\text { engolir os meses e os anos. Estes foram } \\
\text { apreendidos e guardados num calendário, mas } \\
\text { nada a fazia recuar. A vida suportava todos os } \\
\text { caprichos da irmã. A morte engordava sem } \\
\text { parar, enquanto a vida emagrecia e murchava } \\
\text { a olhos vistos. Ela fugiu e foi viver longe, } \\
\text { levando com ela, a cada canto por onde } \\
\text { passava, a alegria e a calma; ao contato com } \\
\text { ela, as árvores floresciam, a terra ficava verde } \\
\text { e a água corria em múltiplos riachos. Mas a } \\
\text { morte a seguia a todo lugar onde fosse e } \\
\text { engolia tudo o que a vida fazia nascer de suas } \\
\text { mãos. Finalmente, a morte engoliu tudo e a } \\
\text { terra se transformou numa bola nua e } \\
\text { desolada. Quando a morte não encontrou nada } \\
\text { mais para comer, caiu no sono. Agitada por } \\
\text { uma forte indigestão, vomitou tudo o que } \\
\text { havia ingerido. Um rio de fel inundou a terra e }\end{array}$ \\
\hline
\end{tabular}




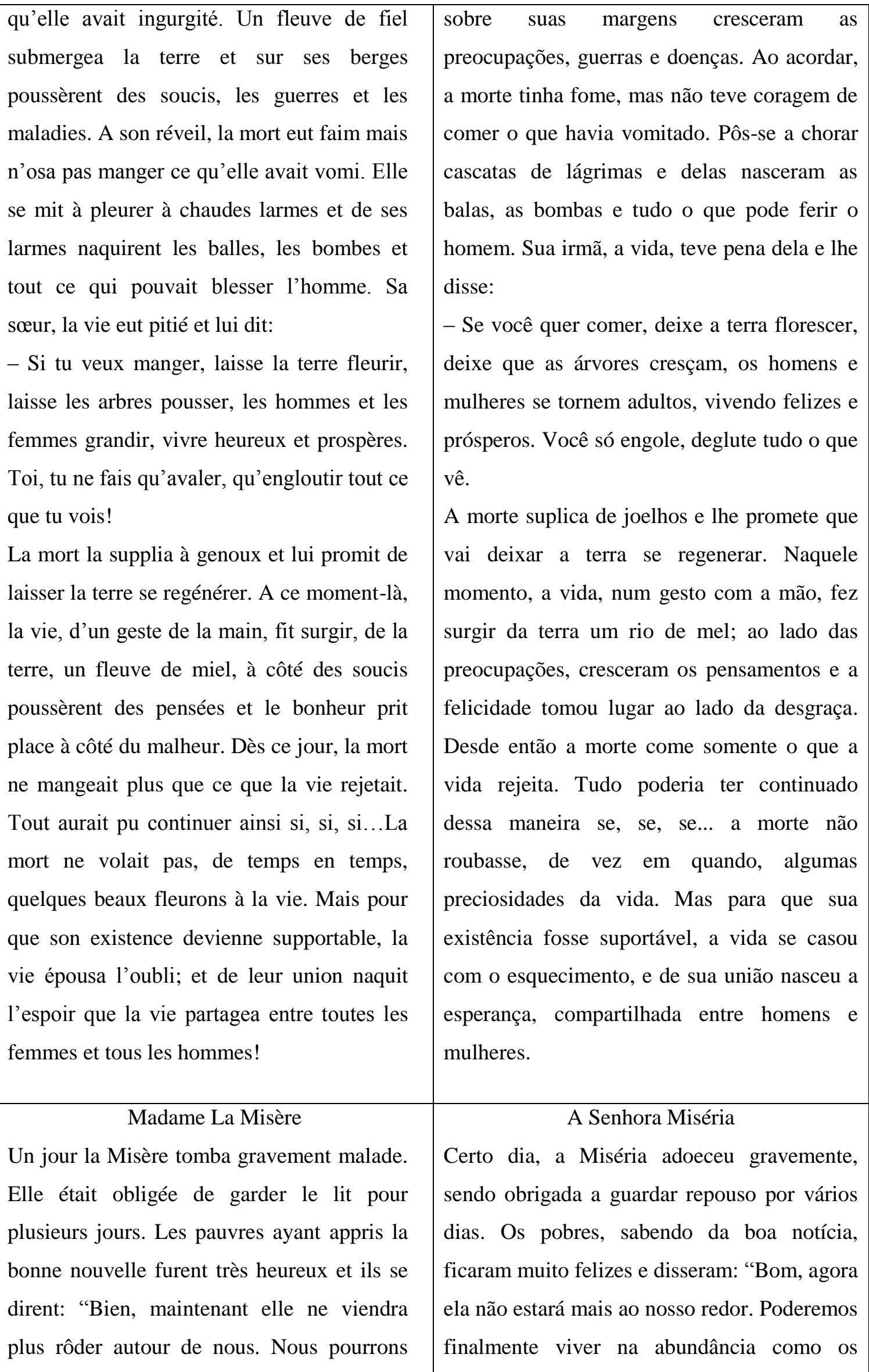


enfin vivre dans l'aisance comme les autres hommes."

Et effectivement, les pauvres sentirent les temps changer, les mendiants ne mendiaient plus, les voleurs ne volaient plus, les affamés mangeaient à leur faim et enfin les pauvres ne l'étaient plus: les guenilles furent jetées aux poubelles, les ceintures desserrées et pour tout dire les beaux jours commencèrent.

Plusieurs jours passèrent ainsi. Cependant l'un des anciens mendiants se mit un jour à réfléchir et se dit :"Pourvu que ça dure! Mais hélas, la Misère finira bien par guérir et j'ai bien peur qu'elle ne revienne nous arracher encore le pain de la bouche! Pourquoi ne pas aller lui rendre visite et lui demander de nous laisser vivre en paix?" Aussitôt dit, aussitôt fait. Il réunit ses amis et leur proposa son idée. Ils la trouvèrent géniale. Alors ils se dirigèrent vers la maison de la Misère. Ils entrèrent chez elle. Elle les reçut fort aimablement. Elle leur dit:"Pourquoi êtes-vous venus me voir?" L'un des pauvres s'avança et dit : "Nous avons appris que tu étais malade, et comme tu as été notre compagne pendant longtemps nous sommes venus te rendre visite, contrairement aux riches qui ne pensent qu'à eux-mêmes..." La Misère se souleva sur son coude et un léger sourire se dessina sur son visage, alors elle leur répondit:

- Je vous remercie beaucoup d'être venus me rendre visite; et puisque les riches ne veulent plus me voir, je n'irai jamais les voir moi non plus! Dès que je serai guérie, je ne outros."

$\mathrm{E}$, de fato, os pobres perceberam a mudança dos tempos, os mendigos já não mendigavam mais, os ladrões não roubavam mais, os famintos matavam sua fome e os pobres deixaram de sê-lo: os andrajos foram jogados nas lixeiras, os cintos foram afrouxados e os dias felizes verdadeiramente começavam.

Muitos dias se passaram assim. Contudo, um dos antigos mendigos pôs-se a pensar e disse: "Tomara que isso dure! Mas infelizmente a Miséria vai sarar e tenho muito medo que ela volte para arrancar o pão das nossas bocas. Por que não lhe fazemos uma visita e pedimos para que nos deixe viver em paz?" Dito e feito. Reuniu seus amigos e propôs a ideia. Eles acharam genial. Foram à casa da Miséria, ali entraram e foram recebidos muito amavelmente. Ela lhes disse: "Por que vocês vêm me ver?" Um dos pobres adiantou-se: "Soubemos que você estava doente, e como é nossa companheira há muito tempo, viemos fazer-lhe uma visita, ao contrário dos ricos que só pensam neles mesmos..." A Miséria levantou-se sobre seu cotovelo, um leve sorriso apareceu em seu rosto, e então ela respondeu:

- Agradeço muito que tenham vindo me visitar; e já que os ricos não querem me ver, eu também não irei vê-los nunca mais! E vocês, logo que esteja curada, não vou lhes abandonar nunca mais! 


\begin{tabular}{|l|l|}
\hline vous quitterai plus! & \\
\hline $\begin{array}{l}\text { Les Melons } \\
\text { Un roi coupait les langues de ceux qui } \\
\text { parlaient, crevait les yeux de ceux qui } \\
\text { regardaient et coupait les oreilles de ceux qui }\end{array}$ & $\begin{array}{l}\text { Os Melões }{ }^{2} \\
\text { furava os olhos de quem olhava e cortava a } \\
\text { orelha de quem escutava. Quando todos os } \\
\text { écoutaient. Quand tous les hommes et toutes } \\
\text { les femmes de son royaume furent ainsi } \\
\text { ablatis, il ne naquit que des enfants sans } \\
\text { langue, sans yeux et sans oreilles. }\end{array}$ \\
$\begin{array}{l}\text { hutilados, somente nasceram crianças sem } \\
\text { língua, sem olhos, sem orelhas. }\end{array}$ \\
\hline
\end{tabular}

\footnotetext{
${ }^{1}$ Currículo Lattes em: <http://buscatextual.cnpq.br/buscatextual/visualizacv.do?id=K4705931H2〉.

${ }^{2}$ São chamadas de "melões" (melons) as pessoas de origem magrebina (marroquinos, tunisianos e argelinos), mas este é um termo fortemente ofensivo e vulgar. [N. da T.]
} 